\title{
Cardia Gland
}

National Cancer Institute

\section{Source}

National Cancer Institute. Cardia Gland. NCI Thesaurus. Code C32261.

Simple tubular or compound racemose type glands located in the region where the esophagus attaches to the stomach which secrete mucus. 